\title{
RESEARCH OF THE PROPERTIES OF DEPOSITION SOLDERING WITH EMBEDDED TUNGSTEN CARBIDES
}

\author{
${ }^{1}$ Petr HLAVATÝ, ${ }^{1}$ Lucie KREJČí, ${ }^{2}$ Miloš MIČIAN, ${ }^{3}$ Jiří HLAVATÝ \\ ${ }^{1}$ VSB - Technical University of Ostrava, Ostrava, Czech Republic, EU, petr.hlavaty@vsb.cz \\ ${ }^{2}$ Technical University of Zilina, Faculty of Mechanical Engineering, Slovak Republic, EU, \\ Milos.Mician@fstroj.uniza.sk \\ ${ }^{3}$ Road and Motorway Directorate of the Czech Republic, Prague, Czech Republic, EU, jiri.hlavaty@rsd.cz \\ https://doi.org/10.37904/metal.2019.899
}

\begin{abstract}
Copper and nickel-based solders with embedded particles of various sizes of tungsten carbide are widely used in industry. These particles are characterized by high hardness and abrasion resistance, erosion resistance, etc. They can be applied both during renovation and in the manufacturing of new parts for decrusters, screw conveyors and other stressed parts. Each of these parts requires a different surface character, and therefore, a different size of the tungsten carbide particles in the tough solder matrix. Machine components with a deposition soldered surface can be classified into the group of composite materials to replace standard parts from quality steels. The tested soldering materials based on $\mathrm{Ni}, \mathrm{Cu}$ were applied to the surface using solder brazing technology on the substrate steel S235JR. The diameter of tungsten carbide particles used in these matrices ranges from $38 \mu \mathrm{m}$ up to $6.0 \mathrm{~mm}$.

This research is focused on assessing the microstructure of selected areas, microhardness measurement and a microstructure analysis using a scanning electron microscope. Using a spot chemical analysis, the movement of partial chemical elements between the base material, solder and carbide particles was investigated.
\end{abstract}

Keywords: Soldering, tungsten carbide, brazing, abrasion resistance

\section{INTRODUCTION}

Wear of machine components especially in construction, the mining industry and agriculture have a negative effect on their durability. These components are then subject to the necessary renovation or total replacement of the given part. At present, new technologies and materials are constantly being developed to increase their resistance to abrasive wear. Deposition soldering is used for the renovation of worn parts as well as for the construction of new extremely stressed machine parts, e.g. (rollers, screw conveyors, teeth for decrusters, etc). When used, these components must withstand both erosive and abrasive wear, especially where soil, wood and aggregates are processed. The powered components thus must meet high demands, both in safety and durability $[1,2]$. This also relates to their resistance to fractions during vibrations and shocks in operation. Improvements to component surface properties can be achieved e.g. by heat sprays, laser cladding, etc. [3,4]. Due to the fragility of tungsten carbide, it is necessary to combine it with a suitable matrix, preventing the premature destruction of the instrument by cracking or by the tungsten carbide particle falling off $[7,9]$. Tungsten carbide is characterized by its high hardness and corrosion resistance $[5,6,8]$.

\section{EXPERIMENT}

For deposition soldering, sticks with a different size of embedded tungsten carbide were used, see Table 1. With different grain sizes, we can also achieve various surface hardness for different applications in practice. The matrices of these solders are for the first two samples No. S01 and No. S02, based on Ni-Cr-B-Si, and for sample No. S03 based on Cu-Ni-Zn. As a basic material for deposition soldering, steel S235 was used for all the samples. 
Table 1 - Distribution of tungsten carbide sizes and solder matrices

\begin{tabular}{|l|c|c|c|}
\hline & Sample S01 & Sample S02 & Sample S03 \\
\hline Solder matrix & WSC $553-\mathrm{Ni}-\mathrm{Cr}$-B-Si & Z-Terradur Ni-Cr-B-Si & Durit CS Cu-Ni-Zn \\
\hline Carbide size & $75-38 \mu \mathrm{m}$ & $1-2 \mathrm{~mm}$ & $4.7-6.0 \mathrm{~mm}$ \\
\hline Flux & & & Borax powder \\
\hline
\end{tabular}
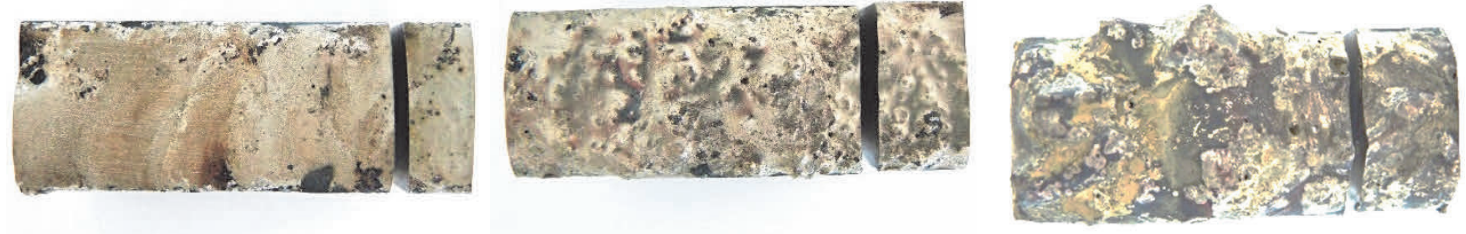

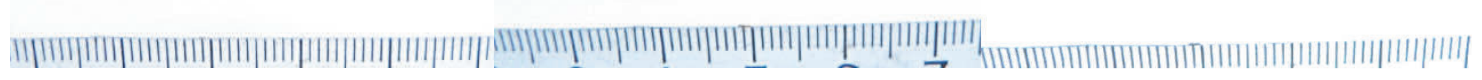

Figure 1 Sample surface S01, S02, S03
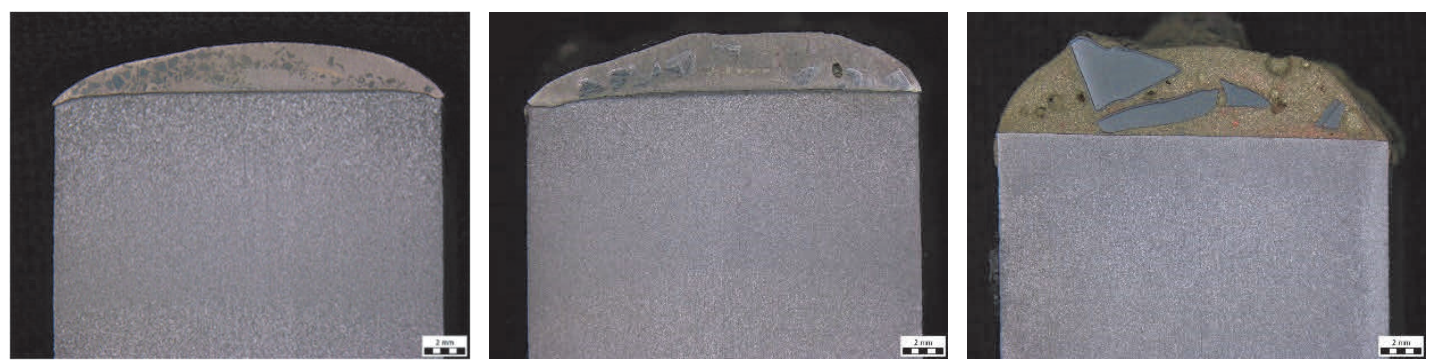

Figure 2 Macroscopic analysis of samples S01, S02, S03

From the initial evaluation of the surface hardness of individual samples, we can conclude their use in practice. Due to its smooth surface with the smallest particles of tungsten carbide 75 - $38 \mu \mathrm{m}$, sample No. S01 has a suitable surface for the application on the edges of cellulose disintegrators and screw gears, where there is increased friction e.g. in the transport of abrasive material. Sample No. S02 with the size of tungsten carbide $1-2 \mathrm{~mm}$ can find a suitable application in the mining equipment. Thanks to higher surface hardness, it helps to separate material better. Sample No. S03 has the largest tungsten carbide sizes of $4.7-6.0 \mathrm{~mm}$, and thus achieves the highest hardness, so this solder is used for woodworking machines, such as decrusters see Figure 1, Figure 2.

\section{MICROHARDNESS}

Due to the heterogeneity of the solder matrix and its own tungsten carbides, a microhardness measurement was performed HV0.1, see Figure 3.

Figure 3 - Hardness measurement HV0.1 done between the solder matrix and the tungsten carbide samples S01, S02, S03

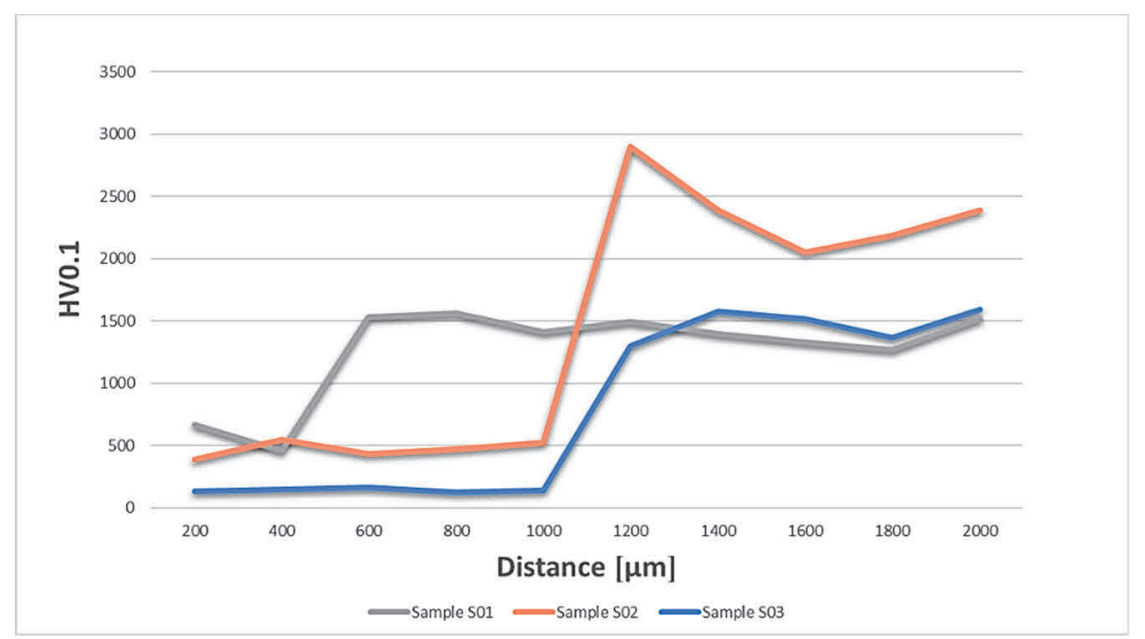




\section{MICROSTRUCTURE}

A further assessment of the samples was carried out by a microstructure evaluation of S01, S02, S03 (Figure 4).
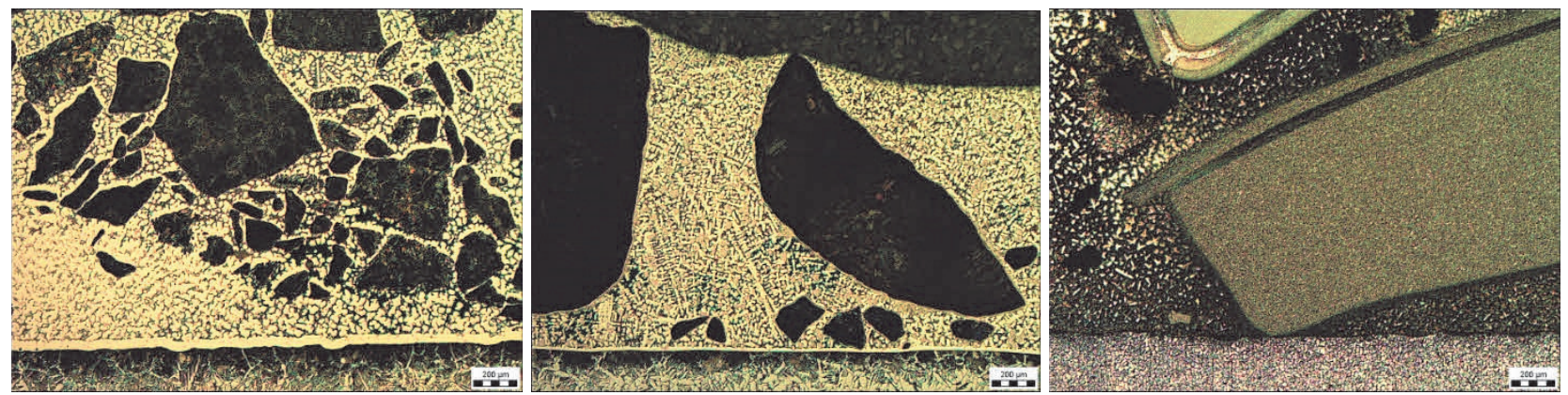

Figure 4 Microstructure of samples S01, S02, S035

\section{CHEMICAL ANALYSIS OF SAMPLES S01, S02 AND S03}

Sample S01 WC - Solder matrix - WC
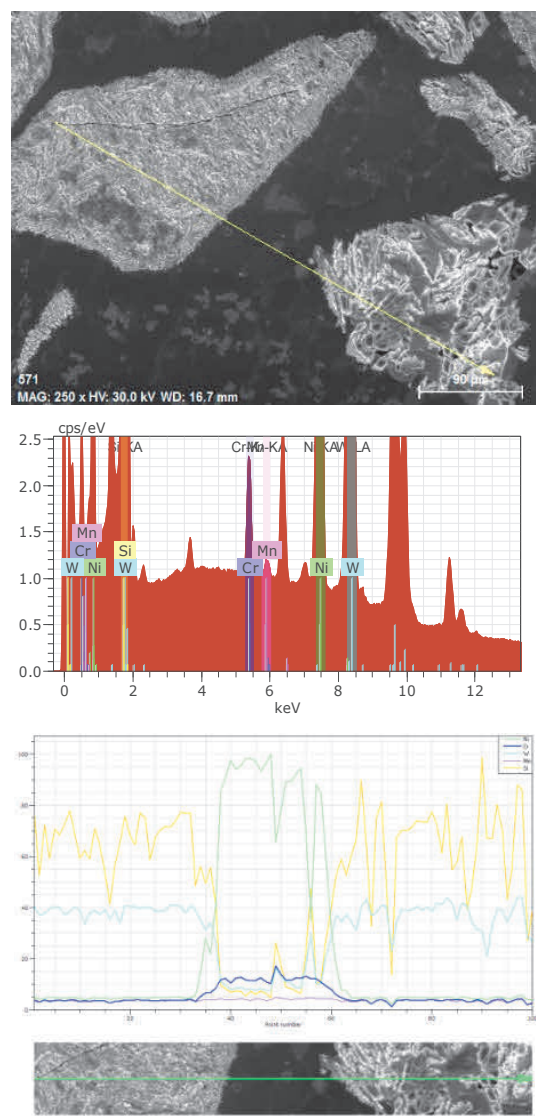

Sample S02 WC - Solder matrix - WC
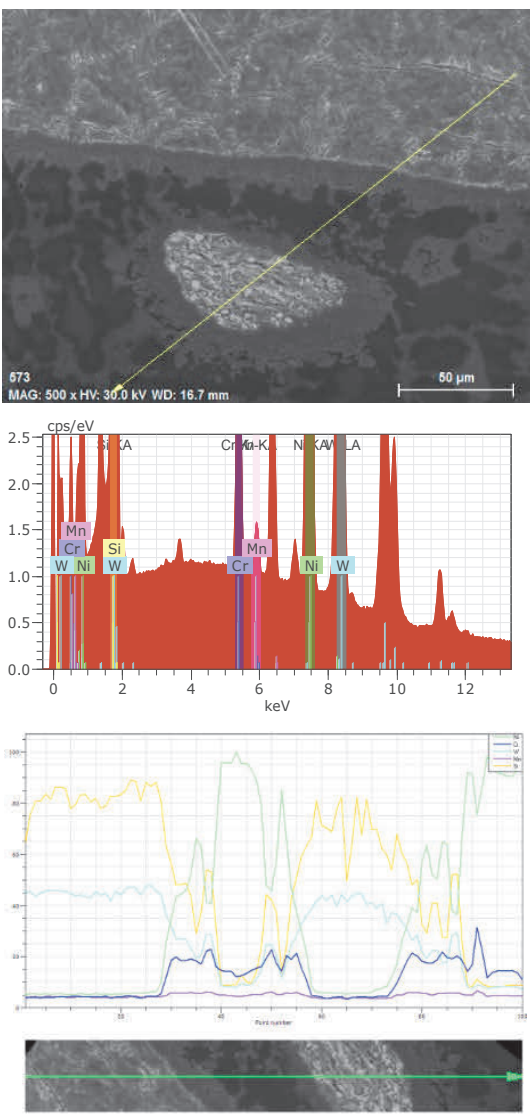

Sample S03 WC - Solder matrix
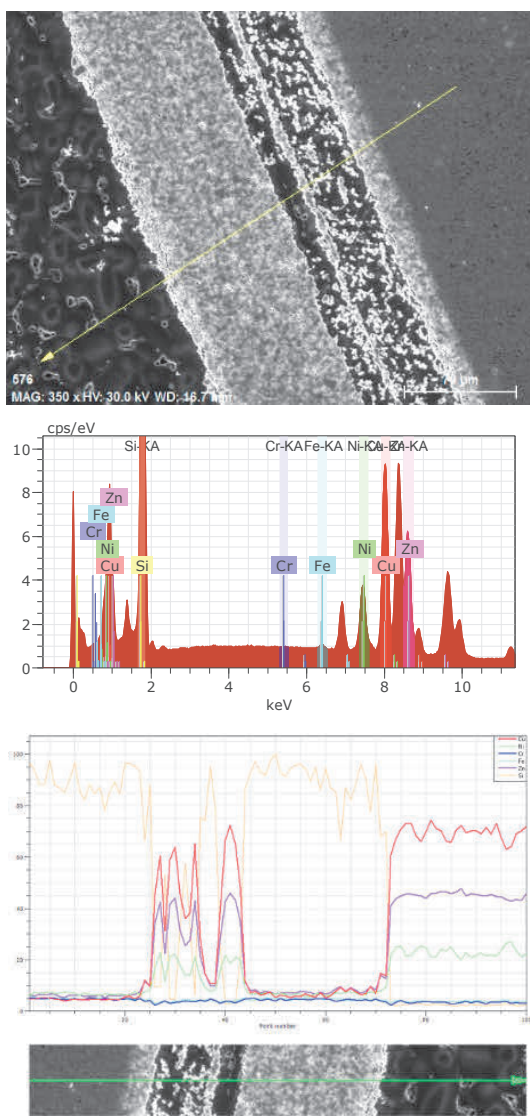

Figure 5 Linear analysis of the individual chemical elements of the sample S01, S02, S03

Line chemical analysis on all samples in Figure $\mathbf{5}$ was measured in the area of transition of tungsten carbide and solder matrix. From the measured values can be seen different chemical composition caused by partial dissolution of the tungsten carbide in a matrix of solder at the same time and the change of mechanical 
properties $[10,11]$. Also in a separate matrix of solder is situated small particles of tungsten carbide, hardened by the matrix [6].

\section{EVALUATION OF RESULTS AND CONCLUSION}

From the results of the sample S01 measurement, where the tungsten carbide is embedded in a nickel-based solder matrix with a size of $75-38 \mu \mathrm{m}$, it can be noted that the hardness of HV0.1 in the matrix is somewhere around $564 \mathrm{HV} 0.1$ and the microhardness of the tungsten carbide particles is $1440 \mathrm{HVO} .1$. The macrostructure shows the uneven distribution of tungsten carbide in the matrix, which is influenced by the technology used. Chemical analysis proves that the particles of tungsten carbide are small, which affects the overall hardness and toughness of the solder.

The S02 sample also has a nickel-based solder matrix with embedded tungsten carbide particles of 1 - $2 \mathrm{~mm}$ in size. The hardness of the solder matrix ranged around $473 \mathrm{HV} 0.1$, but tungsten carbide hardness was around $2383 \mathrm{HV} 0.1$. In terms of macrostructure, the distribution of tungsten carbide is even. Also, when evaluating the chemical analysis, it again confirmed small particles of tungsten carbide in the solder matrix.

The differential copper-based solder matrix used in sample S03 contains the largest embedded tungsten carbide particles with a size of $4.7-6.0 \mathrm{~mm}$. The hardness of the solder matrix ranged around $141 \mathrm{HVO} .1$ and tungsten carbide of $1470 \mathrm{HV} 0.1$. The macrostructure shows that grain distribution is not completely uniform. However, due to the desired roughness, this is desirable for the given use. Evaluation of chemical analysis shows the stable chemical composition of the solder matrix, which is not affected by tungsten carbide.

Deposition soldering technology using solders in the form of sticks containing embedded tungsten carbides is suitable for use in a wide range of applications, for which resistance to the abrasive or erosive wear of the machine part is required, both for renovation and for the construction of new parts with required properties and durability.

The results of the tests show, in addition to the grain size of tungsten carbide, the actual velocity and the heat used for deposition soldering has a big influence. At low soldering speed, and thus with greater heat applied, partial or complete melting of the tungsten carbide grains may occur. This increases the hardness of the matrix at the points with melted grains of tungsten carbide. As a result, different properties of the applied layer can be expected, and thus changes in the abrasion resistance and durability of the applied layers.

\section{REFERENCES}

[1] VAMSI KRISHNA, B., MISRA, V.N., MUKHERJEE, P.S., SHARMA, P. Microstructure and properties of flame sprayed tungsten carbide coatings. International Journal of Refractory Metals \& Hard Materials, vol. 20, 2002, s. 355-374

[2] VERDON, C., KARIMI, A., MARTIN, J.-L. A study of high velocity oxy-fuel thermally sprayed tungsten carbidebased coatings. Part 1: Microstructures. Materials Science and Engineering, vol. 246, 1998, s. 11-24

[3] YAO, Z., STIGLICH, J. J., SUDARSHAN, T.S. Nano-grained tungsten carbide-cobalt (WC/Co). Materials Modification, Inc. [online]. 2012 [cit. 2017-2-24]. < http://www.matmod.com/publications/armor_1.pdf >

[4] MELENDEZ, N.M., MCDONALD, A.G. Development of WC-based metal matrix composite coatings using lowpressure gas dynamic spraying. Surface \& Coatings Technology, vol. 214, 2013, s. 101-109

[5] PRZYBYLOWICZ, J., KUSINSKI, J. Structure of laser cladded tungsten carbide composite coatings. Journal of Materials Processing Technology, vol. 109, 2001, s. 154-160.

[6] HLAVATÝ, I., KOZÁK, J., KREJČí, L. Study of the Weld Deposit Properties Contained Tungsten Carbides in the Iron Matrix. Metal 2016. Brno: 2016, pp. 1056-1060, ISBN 978-80-87294-67-3.

[7] KUBÍČEK, J. Renovace a povrchové úpravy [online]. 11.12.2006 [cit. 2017-2-24].

<http://ust.fme.vutbr.cz/svarovani/opory_soubory/renovace_a_povrchove_upravy_kubicek.pdf> 
[8] HLAVATÝ, I., KOZÁK, J., KREJČí, L., SAMARDŽIĆ, I., TUOMINEN, J. The Effect of Tungsten Carbide Particles Content in a Weld Deposit on its Abrasion Resistance. TEHNICKI VJESNIK-TECHNICAL GAZETTE, Vol. 2017, 24, No. 5, pp. 1345-1349, ISSN 1330-3651 (Print), ISSN 1848-6339 (Online).

[9] JONES, A.H., ROFFEY, P. The improvement of hard facing coatings for ground engaging applications by the addition of tungsten carbide. Wear, vol. 267, 2009.

[10] KOLEŇÁK, R. Solderability of metal and ceramic materials by active solders. Forschungszentrum Dresden, 2008. ISBN 978-3-941405-03-5.

[11] KOLEŇÁK, R.. ŠEBO, P.. PROVAZNÍK, M.. KOLEŇÁKOVÁ, M.. ULRICH, K. Shear strength and wettability of active $\mathrm{Sn3.5Ag4Ti(Ce,} \mathrm{Ga)} \mathrm{solder} \mathrm{on} \mathrm{Al}_{2} \mathrm{O}_{3}$ ceramics. Materials and Design, 2011, Vol. 32, p. 3997-4003. ISSN 0261-3069. 